\title{
O DIREITO ACHADO NA RUA E MEDIAÇÃO: CONVERGÊNCIAS ENTRE ROBERTO LYRA FILHO E LUÍS ALBERTO WARAT
}

\section{Guilherme Macviulevicius Mungo Brasil ${ }^{1}$}

Resumo: A partir da vertente de O Direito Achado na Rua, de Roberto Lyra Filho, que reconhece manifestações jurídicas para além do Estado, surge o problema de pesquisa: como concretizar essa forma não oficial de direito? A hipótese é que a mediação, nos moldes descritos por Luis Alberto Warat, é instrumento adequado para esse fim. O objetivo do trabalho é compreender como O Direito Achado na Rua pode se valer do método da mediação para se efetivar, em um cotejo recíproco entre as ideias que lhes dão base. O trabalho adota o método dedutivo e utiliza pesquisa exploratória, descritiva e bibliográfica.

Palavras-chave: pluralismo jurídico. direito alternativo. direito paralelo. justiça multiportas. resolução consensual.

\section{THE RIGHT FOUND ON THE STREET AND MEDIATION: CONVERGENCES BETWEEN ROBERTO LYRA FILHO AND LUÍS ALBERTO WARAT}

Abstract: From the perspective of Right Found on the Street, by Roberto Lyra Filho, wich recognizes legal manifestations beyond the State, the research problem arises: how to concretize this unofficial form of law? The hypothesis is that mediation, along the lines described by Luis Alberto Warat, is an appropriate instrument for this purpose. The objective of the work is to understand how Right Found on the Street can use the mediation method to become effective, in a reciprocal comparison between the ideas that support them. The work adopts the deductive method and uses exploratory, descriptive and bibliographic research.

Keywords: legal pluralism. alternative law. parallel law. multidoor justice. consensual resolution.

$O$ direito não é; ele se faz, nesse processo histórico de libertação [...]. Nasce na rua, no clamor dos espoliados $e$ oprimidos.

(Roberto Lyra Filho)

Pasaron siglos de normativismo y los juristas continuam teniendo devaneios de recién llegados [...]. Los juristas nunca aprendieron nada de la calle, simpre fueron prisioneiros del misticismo

(Luis Alberto Warat)

\section{CONSIDERAÇÕES INICIAIS}

\footnotetext{
${ }^{1}$ Aluno regular do mestrado em Direitos Humanos da Universidade Federal de Mato Grosso do Sul - UFMS. Graduado em Direito pela mesma instituição. Professor da graduação em Direito do Centro Universitário Anhanguera de Campo Grande/MS (glhrmbrsl@gmail.com).
} 
O Direito, compreendido como plexo de normas que regula a conduta humana, é um fenômeno social não monopolizado pelo Estado. De acordo com a vertente teórica de O Direito Achado na Rua, concebida, em especial, por Roberto Lyra Filho e atualmente coordenada por José Geraldo Souza Júnior, o Direito é algo vivo e dinâmico que emerge de múltiplas fontes, em especial das relações advindas de grupos coletivos coordenados, de suas demandas externas e articulações internas. As ideias de Luis Alberto Warat, igualmente, representam ferrenha crítica ao dogmatismo, relacionando o Direito à sensibilidade humana, seus sentimentos e desejos. Nessa linha, o Direito real é, na verdade, extralegal, não se resumindo ao positivismo. O Direito formal, advindo do Estado, mostra-se, em geral, inefetivo na atividade de regulação social e comumente mero mantenedor do estado de coisas atual, muitas vezes incapaz de garantir avanços sociais.

A concepção de Direito extralegal, alternativo, paralelo, não-oficial, pluralista ou achado na rua dá as bases para a compreensão de formas de Direito que, fugindo da dogmática, criam espaço para promoção de mudanças sociais, possibilitando passos rumo a uma sociedade efetivamente igualitária e justa. Essa saída mostra-se válida pois a História já demonstrou que as formas de avanço social pautadas na mudança do Direito estatal falharam: as revoluções trouxeram consigo estados iguais aos que sublevaram ou até mais perniciosos em relação à defesa dos direitos humanos; a alteração social pela via da produção de leis em Estados minguados e em crise no contexto da globalização, além de fortemente influenciados pelo capital, tampouco tem se mostrado efetiva. A proposta não é (de todo) anárquica e não expurga o Direito estatal, mas reconhece a existência de fontes do Direito que transcendem as meras previsões legais. Dessas questões se ocupará o primeiro ponto do desenvolvimento.

Fixadas essas premissas, surge o problema de pesquisa sobre como concretizar um Direito não positivado, paralelo à atividade legislativa do Estado. É aí que se percebe na mediação, nos moldes dados por Luis Alberto Warat, como forma de solução de conflitos própria de sua Contradogmática do Direito, um espaço que foge da normatividade e que, reconhecidamente, promove emancipação social, uma concepção ativa de cidadania e de aperfeiçoamento democrático. Isso porque, na mediação, as questões postas não são solucionadas por um terceiro, o Estado em sua função jurisdicional, mas pelos próprios envolvidos, empoderados, de acordo não com a lei positivada, mas em conformidade com suas necessidades, expectativas e limitações reais, fortalecendo e aprimorando as relações entre os envolvidos, contribuindo para a cultura da paz. Sobre esse assunto debruçar-se-á o 
segundo e último item do desenvolvimento.

Pretende-se, pois, como objetivo do trabalho, compreender como a concepção teórica de O Direito Achado na Rua pode se valer do método da mediação para se efetivar, em um cotejo recíproco entre as ideias de Roberto Lyra Filho e Luis Alberto Warat - dois grandes expoentes do pensamento crítico do Direito brasileiro -, observado o recorte temático aqui proposto.

O tema se justifica pela necessidade de avanço das teorias do pluralismo jurídico, em especial de O Direito Achado na Rua, bem assim pela atualidade do tema mediação, tendência crescente como forma de solução de conflitos. Ademais, a junção das ideias de O Direito Achado na Rua com o locus de resolução de conflitos próprio da mediação, em que se foge do Direito estatal e se criar um Direito dinâmico e vivo para aquela situação específica, tem a potencialidade de alterar a forma como o próprio Direito e as soluções de conflitos são vistos, estudados e aplicados.

O presente trabalho, situado no campo transdisciplinar da Filosofia do Direito, tem enfoque jurídico-sociológico ${ }^{2}$, e é desenvolvido por intermédio de pesquisa exploratória (é feita a aproximação do objeto de pesquisa ainda pouco estudado), descritiva (descreve-se o estado da arte em relação à temática) e bibliográfica (partirá de fontes secundárias já escritas sobre o tema). Outrossim, metodologicamente, com o escopo de ir além do ensino jurídico das palavras pretas no branco, este estudo, como produto que é da teoria jurídica crítica, valese de imagens e referências a filmes não só com fim didático, mas também com o intuito de possibilitar reflexões a partir de estímulos pouco usuais no campo jurídico e capazes de, a partir da sensibilização dos sentidos, transcender o raciocínio jurídico tradicional.

\section{A PROPOSTA LYRIANA: O DIREITO ACHADO NA RUA}

A lei não é mecanismo de efetiva transformação social. Nunca o foi. Sua gênese e sua lógica estruturante estão intimamente relacionadas ao jugo das pessoas ao sistema capitalista $^{3}$ e à hegemonia dominante ${ }^{4}$. Nas palavras de Lyra Filho:

\footnotetext{
2 “[...] propõe-se a compreender o fenômeno jurídico no ambiente social mais amplo. Analisa o Direito como variável dependente da sociedade [...]. Preocupa-se com a facticidade do Direito e com as relações contraditórias que o próprio Direito estabelece com os demais campos: sociocultural, político e antropológico" (DIAS; GUSTIN. 2013, p. 22).

3 “O direito ocupa um lugar de importância crucial na reprodução das relações sociais capitalistas e é ele que empresta à ideologia burguesa a sua especificidade. De fato, a ideologia burguesa se movimenta inteiramente
} 
A lei sempre emana do Estado e permanece, em última análise, ligada à classe dominante, pois o Estado, como sistema de órgãos que regem a sociedade politicamente organizada, fica sob o controle daqueles que comandam o processo econômico, na qualidade de proprietários dos meios de produção (LYRA FILHO, 2006, p. 3)

A íntima relação entre lei, Estado e capitalismo começa a ganhar corpo com o surgimento dos Estados absolutistas. Com base na filosofia política veiculada no Leviatã de Hobbes $^{5}$, esses poderosos Estados colocam-se como única fonte legítima de regulação social, manifestando sua vontade por meio da lei, isso com o escopo de atender aos interesses da monarquia e de proteger as práticas mercantis prevalentes (WOLKMER, 2015, p. 52). Após a Revolução Francesa, o processo de ascensão da burguesia ao poder, que tinha interesse em legitimar o funcionamento dos novos mercados e a defesa dos novos direitos privados (propriedade e liberdade, em especial), levou à sistematização racional das leis em códigos, com a "definitiva consolidação do reducionismo mítico de todo o Direito à lei estatal, impelindo o pensamento jurídico para o pleno domínio da dogmática jurídica positivista" (WOLKMER, 2015, p. 53). No período entre guerras do século XX, surgiu a "teoria pura" do Direito de Hans Kelsen, segundo a qual “o Estado legitima seu poder pela eficácia e pela validade oferecida pelo Direito, que, por sua vez, adquire força no respaldo proporcionado pelo Estado" (WOLKMER, 2015, p. 60), fundindo, numa só entidade, Direito e Estado. Esse pensamento foi aplicado no contexto de crise e renovação do capitalismo na primeira metade do século passado, embasando a atuação estatal para o restabelecimento das forças produtivas.

Por isso se pode concluir que "o Direito materializado na lei não expressa o verdadeiro significado da justiça, tampouco representa a vontade geral do povo [...], mas os interesses das camadas economicamente dominantes" (WOLKMER, 2004, p. 19).

Roberto Lyra Filho, comungando com essas bases críticas, desenvolve uma distinção entre direito e lei. Para o pensador, como a lei é produção do Estado submetida à vontade da classe dominante, não é possível que a legislação seja considerada, em sua totalidade, direito autêntico, legítimo e indiscutível. Isso porque o direito "autêntico e global não pode ser

dentro do espaço jurídico, a partir das suas categorias fundamentais de 'sujeito de direito', 'propriedade', 'liberdade' e 'igualdade"” (NAVES, 2014, p. 9).

${ }^{4}$ "Na tarefa de construir o direito como consenso hegemônico na sociedade, o fenômeno jurídico deve ser apresentado, ensinado e reproduzido segundo a aparência de uma técnica universal, não comprometida, imparcial, isenta de lados" (MASCARO, 2016, p. 429).

5 “Certamente, assinala-se que Hobbes não é apenas um dos construtores do moderno Estado absolutista, mas igualmente um dos primeiros intérpretes a identificar o Direito como manifestação do Direito do soberano" (WOLKMER, 2019, p. 123). 
isolado em campos de concentração legislativa, pois indica os princípios e normas libertadores, considerando a lei um simples acidente no processo jurídico, e que pode, ou não, transportar as melhores conquistas" (LYRA FILHO, 2006, p. 3). Lyra Filho afirma que:

[...] o Direito resulta aprisionado em conjunto de normas estatais, isto é, de padrões de conduta impostos pelo Estado, com a ameaça de sanções organizadas (meios repressivos expressamente indicados com órgão e procedimento especial de aplicação). No entanto, como notava o líder marxista italiano, Gramsci, a visão dialética precisa alargar o foco do Direito, abrangendo as pressões coletivas (e até, como veremos, as normas não estatais de classe e grupos espoliados e oprimidos) que emergem na sociedade civil (nas instituições não ligadas ao Estado) e adotam posições vanguardeiras, como determinados sindicatos, partidos, setores de igrejas, associações profissionais e culturais e outros veículos de engajamento progressista (LYRA FILHO, 2006, p. 4).

Dessa forma, "a legislação abrange, sempre, em maior ou menor grau, Direito e Antidireito: isto é, Direito propriamente dito, reto e correto, e negação do Direito, entortado pelos interesses classísticos e caprichos continuístas do poder estabelecido" (LYRA FILHO, 2006, p. 3). Portanto, as noções de Direito e lei relacionam-se como dois círculos secantes: comunicam-se em um determinado ponto, em que Direito e lei consubstanciam o mesmo conjunto de fatos sociais reais; mas haverá espectro do Direito real não abrangido pela lei; e, da mesma forma, porção da lei que não corresponde ao Direito real. A relação pode ser assim enxergada:

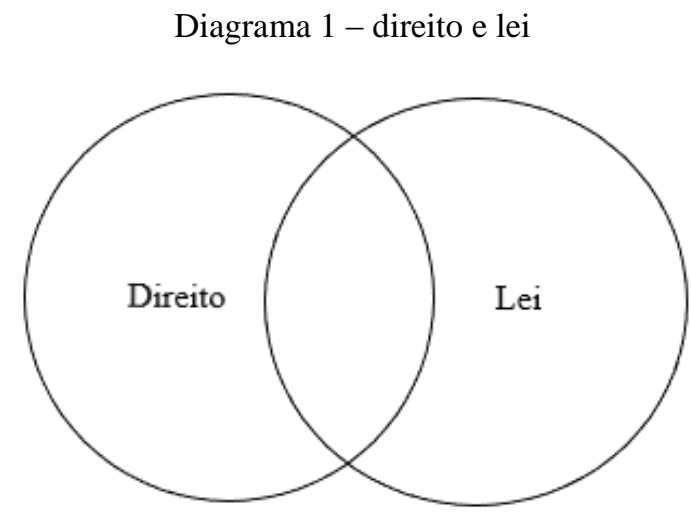

Fonte: própria

Se, porém, o Direito não corresponde integralmente à lei, ao que corresponde? A resposta, conforme Lyra Filho, está na Sociologia Jurídica, uma vez que o direito não diz respeito ao que se pensa sobre o Direito, mas àquilo que juridicamente se faz de forma 
concreta. O pensador propõe uma fuga às concepções abstratas e ideológicas de direito e, como solução, a adoção de um Direito real, baseado na práxis humana (da atividade histórica e social da humanidade) no seu ângulo jurídico. O Direito, portanto, corresponde às práticas reais dialéticas aferíveis por meio de uma análise sociológica do meio social (LYRA FILHO, 2006, p. 29).

É a partir dessas premissas teóricas que os membros da Nova Escola Jurídica Brasileira - NAIR, da Universidade de Brasília - UnB, com destaque para Roberto Lyra Filho, concebem uma vertente de pluralismo jurídico focada na concretização pragmática, isto é, na praxis, de um direito não-oficial: O Direito Achado na Rua. O nome foi retirado por Lyra Filho do epigrama hegeliano número três, de Marx (LYRA FILHO apud SOUSA JUNIOR, 1993):

Kant e Fichte buscam o país distante/
pelo gosto de nadar lá no mundo da lua/
mas eu tento só ver, sem viés deformante/
o que pude encontrar bem no meio da rua

Essa corrente teórica tem uma preocupação que, fugindo do direito dos códigos, ensinado nas faculdades, centra-se nas diferentes formas jurídicas efetivamente praticadas nas relações sociais, superando a aporia juspositivismo versus jusnaturalismo. Assim, é negado o jusnaturalismo em virtude de sua imutabilidade, rejeitando-se a ideia de que os direitos e valores de uma sociedade sejam dados pela natureza, por desígnio divino ou pela elucubração racional; da mesma forma o positivismo é rejeitado por ser uma redução do Direito à ordem estabelecida (LYRA FILHO, 2006, p. 26). O Direito Achado na Rua constrói, com esses elementos epistemológicos, um método próprio:

O sentido que orienta o trabalho político e teórico de O Direito Achado na Rua consiste em compreender e refletir sobre a atuação jurídica dos novos sujeitos sociais e, com base na análise das experiências populares de criação do direito: 1. Determinar o espaço político no qual se desenvolvem as práticas sociais que enunciam direitos, a partir mesmo de sua constituição extralegal, por exemplo, direitos humanos; 2. Definir a natureza jurídica do sujeito coletivo capaz de elaborar um projeto político de transformação social e elaborar a sua representação teórica como sujeito coletivo de direito; 3. Enquadrar os dados derivados destas práticas sociais criadoras de direitos e estabelecer novas categorias jurídicas para estruturar as relações solidárias de uma sociedade alternativa em que sejam superadas as condições de espoliação e de opressão do homem pelo homem e na qual o direito possa realizar-se como um projeto de legítima organização social da liberdade (SOUSA JÚNIOR, 1993, p. 10). 
A partir dessas bases, essa linha teórica concebe o direito da seguinte forma:

O Direito não é; ele se faz, nesse processo histórico de libertação - enquanto desvenda progressivamente os impedimentos da liberdade não lesiva aos demais. Nasce na rua, no clamor dos espoliados e oprimidos, até se consumar, vale repetir, pela mediação dos direitos humanos, na enunciação dos princípios de uma legítima organização social da liberdade (LYRA FILHO, 1986, p. 273, passim).

Dessa forma, a linha de O Direito Achado na Rua entende que o padrão de legitimidade das possíveis fontes do direito não está em seu grau de positivação, mas no vetor histórico e concreto, extraindo, assim "o sumo e o extrato do processo libertador a que se dá o nome de Direitos Humanos (e, note-se, não apenas as declarações, por assim dizer oficiais desses Direitos, porém os Direitos mesmos, emergentes e ainda não 'declarados')" (SOUSA JÚNIOR, 2015, p. 69).

O Direito Achado na Rua começou a ser divulgado, ainda na primeira metade dos anos 1990 do século passado, como um curso de extensão universitária, ofertado a distância pela UnB, sob coordenação de José Geraldo de Sousa Júnior, sucessor de Lyra Filho à frente da linha teórica. O material resultante desse projeto, por se pretender didático e acessível a todos os públicos, é permeado por ilustrações que bem expõem e sintetizam as ideias nucleares dessa linha teórica, a exemplo da seguinte, que faz troça ao direito positivo e à sua ineficácia:

Imagem 1 - O Direito Achado na Rua 


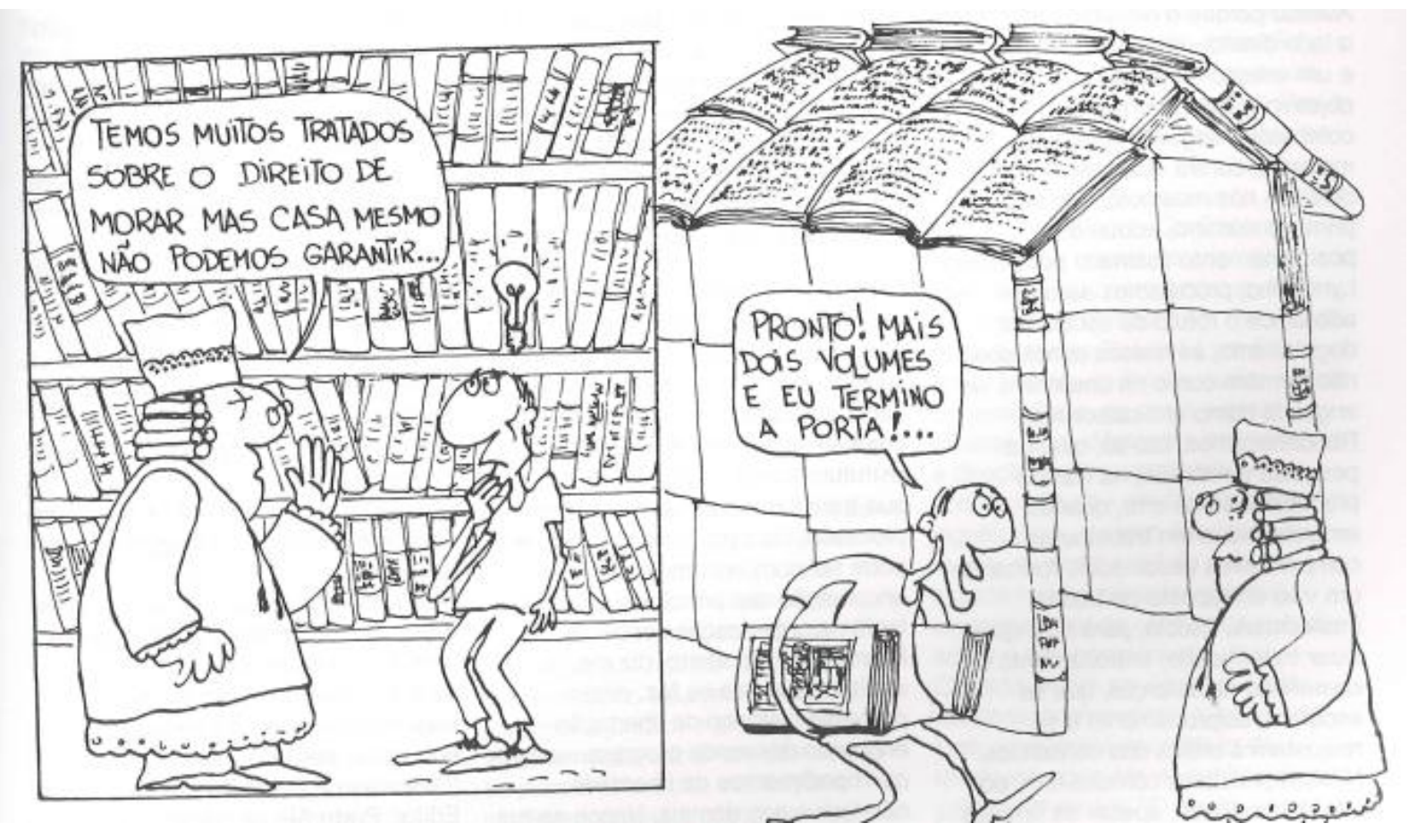

Fonte: SOUSA JÚNIOR, 1993

Também acompanhava o primeiro volume do curso um vídeo, em formato VHS, que introduzia, em linhas gerais, as premissas sobre e criação do direito por fontes populares. Nesse registro, hoje disponível na rede mundial de computadores (MENDES, 1991), veiculam-se exemplos reais das bases e das pretensões de O Direito Achado na Rua. No vídeo, alternam-se imagens que marcaram o fim do século XX no Brasil - em especial de atos pró-democracia e da promulgação da Constituição Federal de 1988 -, breves entrevistas com pessoas diversas na capital federal - na qual lhes é perguntado o que é direito - e exposição de ideias de professores, alunos de direito, advogados e juízes. O que mais chama a atenção, porém, são as falas de Maria de Lourdes e de Maria da Cruz.

Maria de Lourdes, mulher negra e líder comunitária no Distrito Federal, ao falar sobre a sua compreensão de direito, afirma de maneira real e simples que não vê eficácia no “direito no papel” e que as práticas do cotidiano da comunidade e suas reivindicações é que dão as balizas desse direito:

A nossa lei, nós vamos conquistando ela aqui, no dia a dia, no embate dos trabalhos, no embate... na conversação com as pessoas, na negociação com o governo. A gente é que está fazendo... Na verdade é nós que vamos fazendo as nossas leis, porque as leis que estão aí estão só no papel e, na hora da gente querer fazer cumprir isso daí, eles inventam um monte de questões técnicas, um monte de palavras bonitas, que a gente não sabe de onde sai e aí a gente pega e não consegue nada. Então a gente resolveu a gente mesmo ir 


\section{O DIREITO ACHADO NA RUA E MEDIAÇÃO: CONVERGÊNCIAS ENTRE ROBERTO LYRA FILHO E LUÍS ALBERTO WARAT}

fazendo aqui. E a luta do dia a dia mostra isso, mostra que a gente que consegue isso, no dia a dia, nos trabalhos, na organização com o povo. A gente consegue isso é aqui, na prática, porque se a gente for esperar por papel a gente não consegue nada não [sic] (MENDES, 1991).

Maria da Cruz, mulher negra, a respeito da solução de conflito fundiário que envolveu sua comunidade no Distrito Federal, explica, sem se dar conta que fala sobre a criação coletiva e popular do direito, que "se você tem uma perna de linha e você puxa, ela vai quebrar. Mas se você bota muitas perna, ela não vai quebrar, porque ele fica forte. Não consegue quebrar. Muita gente unido é uma força grande. A união forma a força" [sic] (MENDES, 1991).

Ocorre, todavia, que essa forma de conceber o Direito não tem respaldo nas formas tradicionais de tutela e efetivação dos direitos. Isso porque o mesmo modelo de Estado que monopolizou a produção do Direito, reduzindo-o à lei, garantiu um modelo de solução de conflitos também pautado no monopólio da jurisdição. As maneiras informais de produção do Direito, portanto, não encontram espaço de reconhecimento no campo do processo heterocompositivo judicial, marcado "por uma tradição monista de forte influxo kelseniano, ordenada em um sistema lógico-formal de raiz liberal burguesa ${ }^{6 "}$ (WOLKMER, 2001, p. $103)$.

Por essas razões, nota-se a tendência dos públicos do direito a desacatar decisões quando lhes eram desfavoráveis ou quando eram julgadas exclusivamente por critérios formais de direito e não incorporando critérios de justiça substantiva e real. Portanto, faz-se necessário levar a visão de um direito alternativo para um espaço que permita a fuga ao Direito estatal. Os pesquisadores dedicados às propostas de O Direito Achado na Rua já aventaram que "a abertura às novas práticas instituintes de direito como a mediação comunitária e outras formas de resolução de conflitos também podem ser benéficas" (ANTÃO, et al., 2015, p. 247). Daí, em especial, pode-se enxergar convergências entre o Direito Achado na Rua e a mediação descrita por Luis Alberto Warat.

\footnotetext{
6 “[ [...] o Poder Judiciário, historicamente, não tem sido a instância marcada por uma postura independente, criativa e avançada, em relação aos graves problemas de ordem política e social. Pelo contrário, trata-se de um órgão elitista distanciado da sociedade que, quase sempre ocultado pelo 'pseudoneutralismo' e pelo formalismo pomposo, age com demasiada submissão aos ditames dos poderes dominantes e move-se através de mecanismos técnico-procedimentais onerosos, inviabilizando, pelos próprios custos, o acesso à imensa maioria da população de baixa renda" (WOLKMER, 2001, p. 107).
} 


\section{TEORIA CONTRADOGMÁTICA DO DIREITO E A MEDIAÇÃO EM WARAT}

Luis Alberto Warat também se dedicou a abordagens do Direito para além do dogmatismo, propondo uma nova Teoria do Direito, crítica ao senso comum teórico dos juristas, por sua vez pautado no ideal kelesiano "que influi para que o jurista de ofício não seja visto como um operador das relações sociais; mas sim, como um operador técnico dos textos legais" (WARAT, 1982, p. 52-53). Essa leitura de Warat se contrasta não só com o normativismo, mas também com todo o ideário totalizante e racionalizante da Modernidade. Trata-se da "Contradogmática do Direito":

[...] estou trabalhando os arredores, os contornos, colocando os andaimes de uma teoria da alteridade jurídica ou teoria ecológica do Direito. [...] Uma forma radical de aceitação do outro como diferente. Uma maneira de olhar a diferença do outro a partir de um lugar integrativo e não como a ameaça de um antagonismo destrutivo. Um outro não adversarial, colaborativo na aceitação de uma realidade que autorregula seus imprevistos, a complexidade e os paradoxos que surgem de suas diferenças constitutivas. $\mathrm{O}$ Direito da alteridade como emergência de um espaço transacional: a Contradogmática do Direito (WARAT, 2018, p. 48).

As ideias que circundam essa teoria são brilhantemente expostas na obra "A Ciência Jurídica e seus dois Maridos" (2000). Warat faz um paralelo com o romance de Jorge Amado, em que a personagem Dona Flor acaba por ter dois maridos: o falecido Vadinho, representação da boêmia e do id freudiano, que retorna em espírito; e, depois de viúva, casase com o Dr. Teodoro, reprodução da contenção e do superego. Na construção de Warat, Dona Flor - depositária do ego - cede espaço à senhora Ciência Jurídica; Vadinho, ao desejo e à vida; e Dr. Teodoro, ao dogmatismo e ao dever. Nas palavras de Warat:

Vadinho é uma voz do subsolo, um desejo marginal que permite a Dona Flor não ter medo de refletir ludicamente suas contradições. Porém, Dona Flor é uma mulher instituída. Nunca poderia ter um imaginário plenamente marginal. Como muitos de nós, se um princípio de ordem em sua cabeça, desestruturar-se-ia, entraria no delírio. Ela nunca poderia reproduzir Vadinho. Simplesmente necessita dele como o lugar do confronto, para que sua vida não fique neutra.

Dir-se-ia que o segundo casamento de Dona Flor, tal qual o espaço público burguês, transforma o amor em dever, profanando o desejo e a vida. São figuras do autoritarismo: os conflitos se simulam inexistentes e os sujeitos desaparecidos (WARAT, 2000, p. 33). 
Com a contraposição dialética entre Vadinho e Teodoro, Warat, em sua síntese, acaba por afirmar que "as máscaras da ciência do direito são disciplinadoras [...]. Escritos estéreis que não conseguem procriar uma cultura jurídica visceralmente democrática" (WARAT, 2000, p. 44). Por isso, conclui “preciso colocar na ciência jurídica a máscara de Vadinho, imaginada por Dona Flor, para montar minhas instituições subversivas e sublimar a parte maldita da cultura jurídica. Sonho com uma vida intelectual liberada de autoridades [...]" (WARAT, 2000, p. 44). Assim, o autor refuta com veemência os oficialismos:

A rua grita constantemente o excesso, denunciado como as diferenças são ignoradas, reduzidas a minorias excluídas. [...]. Passaram séculos de normativismo e os juristas continuam tendo devaneios de recém-chegados [...]. Os juristas nunca aprenderam nada da rua, eles sempre foram prisioneiros do misticismo nossa (WARAT, 2010, p. 128, tradução nossa ${ }^{7}$ ).

Warat, entretanto, não se limita a criticar o Direito positivista, mas começar a buscar formas de solução de conflitos que dialoguem com sua proposta de concepção do fenômeno jurídico. Nessa caminhada, ele afirma que "quando se decide judicialmente, consideram-se normativamente os efeitos; deste modo o conflito pode ficar hibernado, retornando agravado em qualquer momento futuro" (WARAT, 2018, p. 20). Dessa forma, sustenta que as formas de resolução de conflitos devem oferecer "uma variada gama de procedimentos e estratégias que possibilitam a resolução, com os menores riscos, desgastes emocionais, perda de tempo, custos econômicos elevados e eliminação das imprevisibilidades nos resultados" (WARAT, 2018, p. 25).

Nesse ponto, suas ideias encontram grande ressonância. Na clássica obra de Cappelletti e $\operatorname{Garth}^{8}$ (1988), a denominada "terceira onda renovatória de acesso à justiça" parte da percepção da insuficiência dos meios tradicionais (heterocompositivos e estatais) para a adequada solução dos conflitos humanos. Para tanto, conforme concluem os autores, afigura-se necessário adequar a solução de conflitos a uma crescente preocupação com a

\footnotetext{
7 "la calle grita constantemente la desmesura, denunciando como son ignoradas las diferencias, reducidas a minorias excluídas [...]. Passaron siglos de normativismo y los juristas continúan teniendo devaneios de recién llegados [...]. Los juristas nunca aprendieron nada de la calle, siempre fueron prisioneros del misticismo"

${ }^{8} \mathrm{O}$ italiano Mauro Cappelletti encabeçou, entre os anos 60 e 70 do século XX, um movimento dedicado ao estudo do acesso à justiça, em especial das causas de ineficiência do Judiciário. O conjunto desse trabalho é conhecido como Projeto Florença e os principais resultados foram publicados, por Cappelletti e Bryant Garth, na obra "Acesso à Justiça" (1988). Em seu trabalho, os autores desenvolvem três conjuntos de medidas necessárias para garantir efetivo acesso à justiça, denominando-os de as três "ondas renovatórias de acesso à justiça": assistência judiciária para os pobres; representação dos interesses difusos; e concepção ampla de acesso à justiça.
} 
relação interpessoal existente entre os envolvidos. Deve haver, nessa medida, uma humanização na resolução de conflitos e, para que se atinja esse intento, deve-se adotar "mecanismos de interferência apaziguadora":

[...] Tal como foi enfatizado pelos modernos sociólogos, as partes que tendem a se envolver em determinado tipo de litígio também devem ser levadas em consideração. Elas podem ter um relacionamento prolongado e complexo, ou apenas contatos eventuais. Já foi sugerido que a mediação ou outros mecanismos de interferência apaziguadora são os métodos mais apropriados para preservar os relacionamentos (CAPPELLETTI; GARTH. 1988, p. 26-27).

Nesse contexto, assoma-se a mediação como método autocompositivo de solução de conflitos, que o concebe de maneira positiva, estabelecendo-se, assim, uma cooperação entre os participantes, antes vistos como adversários. São eles, a propósito, os exclusivos responsáveis pelo desfecho da questão controvertida, de modo que há uma quebra da estrutura vertical da jurisdição modernista, possibilitando que a justiça passe a ser praticada de forma horizontal. Warat (2004, p. 65-66), de maneira singela, porém precisa, define o que entende por mediação, qualificando-a a partir de características positivas (presentes) e negativas (ausentes):

\author{
A mediação é: \\ A inscrição do amor no conflito/ \\ Uma forma de realização da autonomia/ \\ Uma possibilidade de crescimento interior através dos conflitos/ \\ Um modo de transformação dos conflitos a partir das próprias identidades/ \\ Uma prática dos conflitos sustentada pela compaixão e pela sensibilidade/ \\ Um paradigma cultural e um paradigma específico do direito/ \\ Um Direito da outridade/ \\ Uma concepção ecológica do Direito/ \\ Um modo particular de terapia/ \\ Uma nova visão da cidadania, dos direitos humanos e da democracia/ \\ [....] mediação em sua identidade específica não é: \\ Uma resolução psico-analítica dos conflitos. \\ Um litígio. \\ Um modo normativo de intervenção nos conflitos/ \\ Um acordo de interesses/ \\ Um modo de estabelecer promessas.
}

Ademais, completa que:

A mediação seria uma proposta transformadora do conflito porque não busca a sua decisão por um terceiro, mas, sim a sua resolução pelas próprias partes que recebem auxílio do mediador para adminstrá-lo. A mediação não se preocupa com o litígio, ou seja, com a verdade formal contida nos autos. 
Tampouco tem como única finalidade a obtenção de um acordo. Mas, visa, principalmente, ajudar as partes a redimensionar o conflito, aqui entendido como conjunto de condições psicológicas, culturais e sociais que determinam um choque de atitudes e interesses no relacionamento das pessoas envolvidas. O mediador exerce a função de ajudar as partes a reconstruírem simbolicamente a relação conflituosa (WARAT, 2004, p. 60).

Com esse conjunto de ideias, Warat concebe, como forma própria de solução de conflitos de sua Contradogmática do Direito a mediação, apontada como a "melhor fórmula até agora encontrada para superar o imaginário do normativismo jurídico" (WARAT, 2004, p. 65). Isso porque, com a mediação, em vez de os envolvidos em determinado conflito recorrerem a uma decisão imposta (goela abaixo) por terceiro (o Estado juiz) que decidirá com base na dogmática jurídica (posta por meio da já criticada lei), são eles próprios que, a partir de suas vivências reais do Direito, chegarão à solução do conflito, assistidos por pessoa que os conduzirá ao aprimoramento do diálogo, de modo que "o intuito de satisfação do desejo substitui a aplicação coercitiva e terceirizada de uma sanção legal ${ }^{9 "}$ (WARAT, 2018, p. 17).

Por essa razão, é possível afirmar que a mediação é instrumento de um modelo de justiça que não se realiza apenas sob o manto da validação judicial e que tampouco está condicionado à correspondência da solução atingida com o arcabouço legal positivado (FREITAS JR., 2014, p. 9). Logo, com a mediação, cria-se um "estado de exceção personalizado" (SPENGLER, 2012, p. 214), cujo locus de manifestação é um espaço livre do Direito estatal e no qual são feitas construções viabilizadoras de transformação social, possibilitando a criação de um campo em que incide um direito achado na rua.

\section{CONSIDERAÇÕES FINAIS}

No presente artigo, foi descrita a linha teórica de O Direito Achado na Rua, de

9 “A mediação seria uma salto qualitativo para superar a condição jurídica da modernidade, baseada no litígio e apoiada em um objeto idealizado e fictício como é o de descobrir a verdade, que não é outra coisa que a implementação da cientificidade como argumento persuasivo; uma verdade que deve ser descoberta por um juiz que pode chegar a pensar em si como protestante de um semi-deus, na descoberta de uma verdade que é só imaginária. Um juiz que decide a partir do sentido comum teórico dos juristas, a partir do imaginária da magistratura, um lugar de decisão que não leva em conta o fato de que o querer das partes pode ser diferente do querer decidido" (WARAT, 2018, p. 23). 
Roberto Lyra Filho, que, ao negar o monopólio do direito pelo Estado, confere legitimidade como fonte do direito a atores sociais coletivamente organizados. Essa vertente, assim, reconhece nas articulações de movimentos sociais o nascedouro de regras jurídicas paralelas às do Estado, em uma abordagem crítica do Direito.

Ocorre que o espaço de efetivação do direito extraoficial não é o processo heterocompositivo judicial. Há uma incompatibilidade inconciliável entre um direito alternativo e o meio do processo estatal. Toda a estrutura de tutela jurisdicional tem profundas raízes no ideário positivista, dogmático, monista e racional próprio à generalidade das elucubrações jurídicas modernistas. A ferramenta judicial, portanto, não serve a um direito achado na rua. Por isso, a organização social comunitária e participativa não apenas cria, em seu processo dinâmico de articulação, um direito informal e extraoficial, mas conduz à adoção de mecanismos de resolução de conflitos igualmente informais e despidos da lógica oficialista de direito.

Nesse cenário, a mediação, em moldes waratianos, assoma-se como o instrumento adequado à efetivação de um direito não oficial. A mediação é espécie do gênero autocomposição, em que os envolvidos no conflito constroem, por si só, a forma de resolvê-lo, em um processo dialético, democrático e empoderador. Na solução de conflitos pela mediação não se aplicam disposições de leis oficiais. Assim, abandonando-se a ideia de efetivação do direito paralelo no campo do processo judicial, o espaço de estado de exceção personalizado criado com o uso da mediação, em que o direito oficial não chega, alinha-se com as premissas e propostas de O Direito Achado na Rua.

Portanto, em suma, é possível afirmar que o processo heterocompositivo jurisdicional está para o Direito monista estatal - adjudicatório e vertical - como a mediação descrita por Warat está para o Direito Achado na Rua de Lyra Filho - emancipador e horizontal.

\section{REFERÊNCIAS BIBLIOGRÁFICAS}

ANTÃO, Renata Cristina do Nascimento, et al. O Direito Achado na Rua: Desafios, Tarefas e Perspectivas Atuais in SOUSA JÚNIOR, José Geraldo (org.). O Direito Achado na Rua: concepção e prática. Rio de Janeiro: Lumen Juris, 2015.

CAPPELlETTI, Mauro; GARTH, Bryant. Acesso à Justiça. Tradução de Ellen Gracie Northfleet. Porto Alegre: Sergio Antonio Fabris, 1988. 
DIAS, Maria Tereza Fonseca; GUSTIN, Miracy Barbosa de Sousa. (Re)pensando a pesquisa jurídica: teoria e prática. 4 ed. Belo Horizonte: Del Rey, 2013.

FREITAS JR., Antonio Rodrigues. Contribuição da Ciência Política para um Conceito Operativo de Conflito e uma Pragmática Responsável da Mediação in FREITAS JR., Antonio Rodrigues (org.). Mediação e Direitos Humanos: temas atuais e controvertidos. São Paulo: LTr, 2014.

LYRA FILHO, Roberto. Desordem e Processo in LYRA, Doreodô Araujo. Desordem e Processo: estudos sobre o direito em homenagem a Roberto Lyra Filho. Porto Alegre: Sergio Antonio Frabis, 1986.

LYRA FILHO, Roberto. O que é Direito. São Paulo: Brasiliense, 2006.

MASCARO, Alysson Leandro. Filosofia do Direito. 5 ed. São Paulo: Atlas, 2016.

NAVES, Márcio Bilharinho. A questão do Direito em Marx. São Paulo: Saraiva, 2014.

O DIREITO Achado na Rua. Direção de Cesar Mendes. Brasília: Centro de Produção Cultural e Educativa da Universidade de Brasília, 1991, 1 vídeo (23m20s) Disponível em: https://www.youtube.com/watch?v=1zOhxb7WyVg. Acesso em abril de 2020.

SOUSA JÚNIOR, José Geraldo. O Direito Achado na Rua: concepção e prática. Plataforma para um Direito emancipatório in SOUSA JÚNIOR, José Geraldo (org.). O Direito Achado na Rua: concepção e prática. Rio de Janeiro: Lumen Juris, 2015.

SOUSA JÚNIOR, José Geraldo. O Direito Achado na Rua: concepção e prática in SOUSA JÚNIOR, José Geraldo (org.). Introdução crítica ao direito. 4 ed. Brasília: Universidade de Brasília, 1993.

SPENGLER, Fabiana Marion. Fundamentos Políticos da Mediação Comunitária. Ijuí: Editora Unijuí, 2012.

WARAT, Luis Alberto. A ciência jurídica e seus dois maridos. 2. Ed. Santa Cruz do Sul: EDUNISC, 2000.

WARAT, Luis Alberto. A Rua Grita, Dionísio! Direitos humanos da alteridade, surrealismo e cartografia. Rio de Janeiro: Lumen Juris, 2010.

WARAT, Luis Alberto. Ecologia, Psicanálise e Mediação in WARAT, Luis Alberto (org.). Em Nome do Acordo: a mediação no direito. Florianópolis: Modara, 2018.

WARAT, Luis Alberto. O Ofício do Mediador in DAL RI JÚNIOR, Arno et al (org.). Surfando na Pororoca: Ofício do mediador. Florianópolis: Fundação Boiteux, 2004.

WARAT, Luis Alberto. Saber crítico e Senso Comum Teórico dos Juristas. Revista Sequência, v. 3 n. 5, 1982, p. 48-57. 
WOLKMER, Antonio Carlos. História do Direito: tradição no Ocidente e no Brasil. 11 ed. Rio de Janeiro: Forense, 2019.

WOLKMER, Antonio Carlos. Marx, a Questão Judaica e os Direitos Humanos. Revista Sequência, n. 48, julho de 2004, p. 11-28.

WOLKMER, Antonio Carlos. Pluralismo Jurídico: fundamentos de uma nova cultura no Direito. 4 ed. São Paulo: Saraiva, 2015. 